\title{
Analysis of Entrepreneurial Process Based on Domestic Introduction of Sport Contents: Focusing on the Innovation Diffusion Process Model
}

\author{
Kisung Kwon', Taeyeon $\mathrm{Oh}^{2}$, Jihyun $\mathrm{Le}^{3}$ and Jeehyun $\mathrm{Kang}^{3 *}$ \\ ${ }^{1}$ Department of Sport Science, Kangwon National University, Kangwon, Korea \\ ${ }^{2}$ Department of Health, Exercise Science \& Recreation Management, University of Mississippi, Oxford, MS \\ ${ }^{3}$ Department of Physical Education, Seoul National University, Seoul, Korea
}

[Purpose] A number of start-ups in the form of introducing sports contents in Korea as a new market are in progress, and appropriate support for each step is needed to increase the chances of a success. Therefore, the purpose of this study is to explore the entrepreneurial process of introducing and spreading newly created or developed sports content into a new market, Korea, by focusing on the innovation diffusion process model. [Methods] To derive the results, a qualitative research method was used, data were collected through in-depth interviews, literature search, and observation methods, and analyzed through categorization and itemization in stages based on content analysis results. [Results] Looking at the results, content recognition and problem identification were derived in the exogenous shocks stage, and the organization unity of internal and external stakeholder was confirmed in the formal coalition of opinion leaders stage. At the stage of internal communication between the opinion leaders of the social system, the expert communication in the same or similar field and external area appeared and the indirect experience also derived. In the decision to select a specific innovation stage, activities to belong to an international organization, to establish a new organization, and to secure idle space appeared, and at the stage of recruitment and/or the establishment of boundary spanners, efforts to secure internal and external human resource within the organization and to build an organization form appeared. In the stage of develop and introduce the innovation, online communication channels were established. In the stage of using mass media outlets, media articles, lectures, and academic conferences were used, and in the stage of actual diffusion of an innovation, experience and education programs were conducted, competition and exhibitions were held, venues were built, and actual international competitions were participated. At the stage of decisions to continue, discontinue, or re-invent the existing innovation must occur, evaluation was made by personnel inside and outside the organization. [Conclusions] It is possible to increase the success of start-up by creating a support system that can fill the necessary parts for each stage of start-up based on the derived activities for each stage.

Key words: Entrepreneurship, Entrepreneurial process, Start-up, Sport start-up, Sport content, Innovation diffusion process model.

논문 투고일 : 2021.01.07.

논문 수정일 : 2021.03.15.

게재 확정일 : 2021.05.11.
* 교신저자 : 강지현(jeehyunkang@snu.ac.kr)

* 2020년도 강원대학교 대학회계 학술연구조성비로 연구하였음. 


\section{서 론}

\section{연구의 필요성}

한국 스포츠 시장에서는 이 세상에 선보이지 않은 제품 또는 서비스를 만들어 내기 위한 다양한 형태의 창업 활동이 나타나고 있다. 다양한 창업 활동의 모습 중, 해외에서 만들 어진 제품과 서비스를 국내 스포츠 시장에 도입하여 이를 사 업화하는 창업도 존재한다. Peres, Muller, \& Mahajan (2010)의 연구에서는 정보통신기술이 발전하면서 광범위 한 의사소통이 가능해져 새로운 스포츠 종목이나 문화도 아 주 빠르게 전파된다고 주장했다. 즉, 정보통신의 발달로 새 로운 콘텐츠를 받아들이는 방식은 용이해졌으며, 해당 콘텐 츠가 확산되는 기간은 현저히 단축되었다. 이러한 사회문화 적 맥락을 고려할 때 해외의 새로운 콘텐츠를 국내 시장에 도입하는 형태의 창업에 주목해 볼 필요가 있다.

매년 70여 개국, 만 개 이상의 업체가 참가하는 골프 박 람회(PGA Merchandise Show)는 미국 프로 골프 협회 (Professional Golf Association, 이하 PGA) 주관으로 4 만 명 이상이 박람회에 참여한다(PGA, 2017). 골프 박람회 를 찾는 사람들의 다양한 목적 중 하나는 골프 관련 새로운 콘텐츠 발굴이다. 이들은 자신의 국가에 소개되지 않은 새 로운 콘텐츠를 도입하여 새로운 시장을 만들고자 한다.

창업은 누군가가 발견한 특정한 기회가 발단이 되는 특징 을 지닌다(Busenitz, West III, Shepherd, Nelson, Chandler, \& Zacharakis, 2003). 창업가는 새로운 기회를 찾아 나서고 기회 발견을 통해 사업을 발전시켜 나갈 수 있는 동력을 얻게 된다(Logan \& Ganster, 2007; Lumpkin \& Lichtenstein, 2005; Fiet, 2007). 기회는 새로운 방법과 결 과물 또는 이들 간의 관계를 통해 새로운 시장이 생기고 원자 재와 함께 새로운 상품으로서의 제품과 서비스가 나타난 상 황으로 정의된다(Casson, 1982; Eckhardt \& Shane, 2003; Shane \& Venkataraman, 2000).

기회를 바탕으로 하는 창업은 새로운 방법과 결과물, 이 들 간의 관계를 통해 새로운 수익을 창출해 낼 수 있는 가능 성이 존재하며 기존의 재화나 서비스의 효율성을 증대시킬 수 있다. 하지만 일반적인 기업 조직의 경우 이러한 기회를 이용하여 새로운 사업을 기획하기 보다는 재화나 서비스의 생산 능력을 최적화시키기 위한 노력에만 집중하는 경향이 있다(Kirzner, 1997).
보다 구체적으로 기회는 창의력과 학습에 기반 한 새로운 생각에서 시작되며(Short, Ketchen, Shook, \& Ireland, 2010) 이를 잘 활용할 경우 창업이 이루어질 수 있다 (Dimov, 2007). 구체적으로 시장 요구에 부응하는 새로운 생각을 통해 생산된 가치가 시장 내 다양한 주체 및 자원들 과 융합되는 과정에서 기회가 생성되며 이는 새로운 가능성 으로 발전될 수 있다(Casson, 1982; Israel, 1973; Schumpeter, 2013). 이에 더해, 기회를 잘 활용하여 시장 의 요구에 맞는 가치를 만들어 낼 수 있다면 창업은 현실화 될 수 있다(Schroeder, Buckman, \& Cardozo, 1996).

Alvarez, Barney, \& Young (2010)의 연구에서는 기회 를 현실주의, 구성주의, 진화론 측면의 접근을 통해 설명하 고 있다. 현실주의적 접근 방식에서 기회는 특정 개인이 독 점적으로 인지하며 특별히 감추고 있다는 가정을 전제로, 객관적으로 존재하고 있으나 눈에 보이지 않는 것이라 정의 한다. 구성주의적 접근 방법의 경우 기회란 개별 사람의 현 상, 재료, 자원에 대한 다른 해석을 통해 생성되는 것으로 가 정한다. 진화론적 접근은 현실주의적 접근과 구성주의적 접 근 간 갈등 축소에 초점을 두며, 시행착오를 통해 보이지 않 은 변화가 나타난 부분을 기회라고 정의한다.

기회를 정의하는 다른 접근으로 Sarasvathy, Dew, Velamuri, \& Venkataraman (2003)의 연구는 배분적 (Allocative), 발견적(Discovery), 창조적(Creative)과 같 은 관점을 통해 창업 기회를 설명한다. 여기서 배분적 관점 에서의 기회는 목표 달성을 위해 자원을 투입할 수 있는 가 능성으로 정의된다. 발견적 관점은 기회를 목표를 달성하기 위해 오류를 수정하고 새로운 방법을 고안해 낼 수 있는 가 능성이라 제시하였다. 창의적 관점에서 기회란 새로운 방법 과 이로 통해 만들어지는 결과물에 초점을 맞춘다.

이러한 선행 연구들에서 제시하고 있는 기회에 대한 정의 와 관점을 통해 특정 국가 또는 시장 밖 어디선가 이미 만들 어진 스포츠 관련 콘텐츠를 국내의 새로운 시장에 도입하는 것을 창업으로 볼 수 있는지에 대해 확인해 볼 필요가 있다. 이유는 이러한 형태의 창업을 단순한 수입유통과 같은 사업 으로 간주할 수도 있기 때문이다.

앞서 제시한 선행연구에 따르면 창업이 기반하고 있는 기 회란 새로운 방법과 결과물, 방법과 결과물 간의 관계를 바 탕으로 나타난 상황들 속에 새로운 시장을 포함하고 있다 (Casson, 1982; Eckhardt \& Shane, 2003; Shane \& Venkataraman, 2000). 또한 현실주의적 접근에서는 이미 
존재하지만 관찰되지 않는 것을 기회라고 설명하고 있으며 할당적 관점에서는 목표 달성을 위해 자원을 투입할 수 있는 가능성을 기회라고 제시하고 있다. 이를 통해 특정 콘텐츠 를 새로운 시장에 도입하는 부분은 하나의 기회로 해석될 여 지가 있으며 이러한 기회를 바탕으로 진행되는 사업을 창업 으로 간주할 수 있다.

다만, 기회를 발전시켜 창업을 시작하더라도 이에 대한 성공 여부는 보장되지 않는 것이 현실이다. 정부와 민간의 창업 활성화 노력에도 불구하고 국내 창업여건은 밝지가 않 다. 구체적인 수치를 살펴보면 세계기업가정신발전기구 (Global Entrepreneurship Development Institute)에 서 발표한 세계창업지수에 의하면 2015년과 2016년 기준 OECD 34개 국가 중 한국은 27위인 하위권을 차지하고 있 다. 또한 2020년 기준, 창업 후 5년간 생존 가능한 기업들의 비율이 프랑스, 영국, 이탈리아, 스페인, 독인, 핀란드 등은 $38 \%$ 에서 $48 \%$ 사이로 나타나는 것에 비해 한국은 $29.2 \%$ 에 불과한 실정이다(Kim, 2020, September).

이러한 상황 속에서 국내 스포츠 시장 내 존재하는 창의 적인 생각들을 성공적인 창업으로 연계시키기 위해서는 정 부와 민간 차원의 노력이 필요하다. 관련된 노력의 일환으 로 창업이 시작되는 시점부터 지속 가능한 사업 형태로서 안 착되거나 다른 기업이 회사를 인수하는 단계까지의 일련의 활동을 구체적인 창업 과정으로 체계화하여 각 단계에 적합 한 지원 위한 노력이 나타나고 있다. 그 예시로서 2020년 중소벤처기업부의 창업 지원 사업을 살펴보면 초기창업패 키지, 창업도약패키지, 글로벌 엑셀러레이팅으로 구분하여 사업을 진행하고 있다.

창업 과정의 각 단계에 적합한 지원을 통해 창업 성공 가 능성을 높여가기 위해서는 단순한 기회 발견 단계부터 시작 하여 각 성장 단계 별로 나타나는 활동들에 대한 면밀한 분 석이 필요하다. 이러한 분석을 통해 세부 단계별로 창업 초 기 세운 목표를 달성하고 사업의 지속 가능성을 확보해 나가 는데 있어 영향을 미치는 촉진요인과 저해요인을 찾아낼 수 있다. 더 나아가 특정 콘텐츠가 어떠한 과정과 방식으로 새 로운 시장에 도입, 전파, 확산되어 나가는지에 대해 파악할 수 있다.

본 연구에서 초점을 맞추고 있는 스포츠 콘텐츠는 사회 문화로써 일정한 단계를 거쳐 확산되어 나가는 모습을 보이 며 각 단계는 사업의 성공과 긴밀히 연계되어 있다. 이는 문 화적 확산이라는 개념과 연계시켜 설명 가능하다. 확산은
혁신이 전파되는 과정을 설명하며 주로 근대화에 기반을 두 고 진행되어 왔다(Strang \& Meyer 1993). 예컨대, 사회 구 조라는 개념은 근대화를 통해 확산되었다고 설명한다.

이러한 연구들을 통하여 혁신이 확산되어 나가는 과정에 대한 관심이 높아짐에 따라 Rogers (2003)는 혁신 확산 이 론을 제시하였다. 구체적으로 사회 일부 구성원은 특정한 채널을 통해 새로운 형태의 혁신을 받아들이게 된다는 개념 을 제시하였다. 확산이 가능한 혁신은 현재의 관념 또는 기 술에 비해 상대적 효율성이 높아야 하며 혁신을 받아들이는 사람의 가치, 경험, 욕구와 일치하는 속성을 지닌 것으로 설 명하였다.

또한 특정한 혁신이 다른 사람들에게 전달되고 시간이 지 남에 따라 혁신의 범주 밖에 존재하는 사회 구성원이라도, 새로운 또는 다른 혁신을 받아들일 가능성이 있다는 것을 일 련의 과정을 통해 설명했다. 구체적으로 혁신을 받아들이는 사람들은 초기에 이를 인지하고 태도의 변화로 이어지며 최 종적으로는 행동의 변화까지 만들어 낼 수 있다고 설명하였 다. 보다 세부적으로 사람들은 혁신을 수용하는데 있어 인 지, 관심, 평가, 사용, 수용과 같은 단계를 거치는 것이며 관 련된 주요 요소로서는 정보원, 메시지, 매체, 수용자, 효과 를 제시하였다.

하지만 해당 이론의 한계점은 비록 혁신 확산과 관련하여 의사소통 채널 등과 같은 매개체에 대해 언급하였지만 이러 한 매개체에 대한 구체적인 역할과 진행 과정에 대한 설명이 부족하다는 것이다(Seifried, Katz, \& Tutka, 2017). 이러 한 선행 연구의 제한점을 바탕으로 Seifried, Katz, \& Tutka (2017)의 연구에서는 9가지 상호 작용 단계를 통해 미국 군대 내에서 볼링이라는 스포츠가 확산되어 나가는 사 례를 중심으로 혁신 확산 과정을 도출하였다.

구체적으로 초기 3단계까지는 외부 충격(exogenous shocks), 선도자와의 연합(formal coalition of opinion leaders), 사회 체계 내 선도자와의 소통(internal communication between the opinion leaders of the social system)과 같은 과정이 나타났다. 이를 바탕으로 구 체적인 혁신 선택(decision to select a specific innovation), 혁신을 위한 인력 확보 및 조직 구성 (recruitment and/or the establishment of boundary spanners), 혁신의 발전 및 전파(develop and introduce the innovation)와 같은 과정을 제시하였다. 이후에는 사 용가능한 미디어 활용(mass media outlets), 혁신의 실제 
적 확산(actual diffusion of an innovation), 혁신에 대 한 지속 여부/재혁신 여부 결정(decisions to continue, discontinue, or re-invent the existing innovation must occur)과 같은 과정이 실행되는 것으로 나타났다.

이러한 스포츠 콘텐츠 도입을 통한 창업 과정에 혁신 확 산 과정 모델을 적용해 보았을 때 콘텐츠를 새로운 시장에 도입하고 이를 확산시켜 나가는 과정을 보다 체계적으로 구 분하여 살펴볼 수 있다. 더 나아가 도출된 결과를 바탕으로 하여 창업 시 설정한 가치를 달성하고 사업에 대한 지속 가 능성을 높여 갈 수 있는 구체적인 방안을 모색하는데 있어 근간이 될 수 있어 본 연구는 이에 초점을 맞추었다.

\section{연구목적}

이러한 배경으로 본 연구의 목적은 해외에서 새롭게 생성 되거나, 선진화된 형태의 스포츠 콘텐츠를 국내시장에 새롭 게 도입하여 확산시켜 나가는 창업 과정을 기존 연구에서 제 시한 혁신 확산 과정 모델을 적용하여 탐험적으로 분석하는 것이다.

\section{연구방법}

본 연구는 결과 도출을 위해 질적연구방법을 활용하였다. 창업 과정 중에서도 스포츠 맥락에서 창업의 성공 가능성을 높이기 위해서는 각 단계 별 맞춤형 지원이 필요하다. 하지 만 창업이 진행되는 과정 별 세부적인 활동에 대한 연구가 제한적인 상황에서 추후 진행될 연구의 기본 방향을 보여주 기 위한 연구방법으로 본 연구 수행을 위해 질적연구방법이 적합하다고 판단하였다(Altheide, 1996; Creswell, 2003; Eagleman, 2011).

연구결과에 대한 신뢰성 확보를 위해 창업에 경험이 있고 스포츠경영을 전공하는 석사 및 박사 과정 학생 3 명을 코더 로서 참여시켜 단계별 과정에 따라 자료를 분석하였다. 이 러한 부분이 연구의 신뢰성과 연계될 수 있는 이유는 질적연 구의 신뢰성 확보를 위해서는 정확한 연구 기법을 사용하였 는지가 중요하기 때문이다. 연구 기법의 정확성을 향상시키 기 위해 우선 외부 코더 참여를 통해 연구자의 주관성을 배 제시켰고 체계화된 단계별 분석 진행을 통해 합의가 이루어 지는 과정을 객관화하였다. 또한 타당성 확보를 위해서는
삼각측정법을 활용하였고 심층면담 대상 선정에 있어서도 공동창업자, 임원, 구성원, 자문 위원을 모두 포함시켜 진행 하였다.

\section{연구대상 및 자료수집방법}

연구대상은 풋골프, 여자축구, 스트릿컬처와 같은 스포 츠 관련 콘텐츠를 국내에 도입하여 확산시키는 것을 목적으 로 하는 주체를 연구대상으로 설정하였다. 이유는 새롭게 창업이 시작된 시기가 유사하고 새롭게 생성 또는 발전된 스 포츠 콘텐츠를 새로운 시장이라 할 수 있는 국내에 도입하기 위한 창업 활동이 이루어지고 있는 조직이기 때문이다.

풋골프는 발과 축구공을 사용하는 것 이외에는 골프장을 사용하고 골프 규칙과 경기 규칙이 유사하여 골프를 바탕으 로 하여 새롭게 탄생한 스포츠이다. 2012년에 국제연맹이 처음 창설되었으며 국내에는 2016년에 처음으로 소개되었 고 이후 적극 도입을 위한 노력이 이루어졌다. 여자축구는 대회 출전을 위한 대표 선수 중심의 엘리트 선수 활동은 있 었지만 여성 축구 동호인들을 대상으로 하는 문화는 거의 형 성되어 있지 않은 상황이어서 이를 활성화하기 위한 움직임 이 나타났다. 스트릿컬처는 일반적으로 서브 문화로서 인식 되고 있으며 스포츠와 연관 지을 경우에는 엑스게임의 형태 로 알려져 있다. 엑스게임에 포함된 대표적인 하계 종목으 로는 스케이트보딩, BMX가 있으며 동계 종목으로는 기존 의 전통적인 종목과 다른 유형의 스키와 스노보딩이 있다.

자료수집을 위해 삼각검증법을 활용하였으며 자료탐색, 심층면담, 관찰과 같은 방법을 활용하였다. 주요 자료 수집 대상을 각 조직이 운영하고 있는 사회관계망서비스(이하 SNS)에 게재한 콘텐츠로 설정하였으며 2017년 1년간의 콘 텐츠를 수집하였다. SNS 상의 게재된 콘텐츠를 자료 탐색 의 대상으로 설정한 이유는 대부분의 창업 조직의 경우 SNS 를 주요 소통 채널로 사용하고 있고 활동 내역 관련 콘텐츠 를 시기 순으로 올리고 있기 때문이다.

심층면담의 경우 조직 별로 3명, 총 9명을 대상으로 하였 으며 2017년 1년 동안 창업 활동 내역에 대한 자료를 수집 하였다. 다만 2018년의 경우 결과 도출에 있어 필요한 부분 이 있을 시 추가적인 심층면담을 진행하였다. 심층면담 대 상은 조직 별 3명이 참여하였으며 각각 공동창업자, 임원, 구성원, 자문위원 중에서 구성되었다. 각 조직 창업자의 경 우 본 연구의 저자로서 참여하고 있어 주관적 평가와 판단이 
개입될 여지로 인해 면담 대상에서 제외하였다. 심층면담은 해당 기간 동안에 주기적으로 각 대상 별 최소 3 회에서 최대 7회까지 진행하였다. 대상자에 대한 구체적인 정보는 〈Table $1>$ 을 통해 제시하였다.

마지막으로 관찰의 경우 해당 조직이 주관 또는 주최하는 이벤트 및 유관 회의 참관을 통해 자료를 수집하였다. 자료 수집을 진행하는데 있어서 연구자가 관련 있는 조직이 아닌 다른 조직에 대한 관찰 자료만을 분석 자료로써 활용하였 다. 관찰을 통한 자료 수집은 2017년 1년간 진행되었으며 관찰 빈도는 이벤트의 경우 평균적으로 2회 정도, 회의 참관 은 평균 5회 정도 이루어졌다.

연구결과 도출을 위해 수집된 자료들은 수집 시기에 무관 하게 분석해 볼 가치가 있다고 판단하였다. 왜냐하면 현실적 으로 유사한 시기에 스포츠 콘텐츠를 새로운 시장에 도입한 사례를 찾고 이와 관련된 자료를 수집하기 어렵기 때문이다.

\section{자료분석방법}

창업 경험이 있으며 스포츠경영을 전공하고 있는 석사 및 박사 과정생 3 명이 코더로서 자료분석에 참여하였다. 이를 통해 연구 대상이 되는 3 개의 조직과 연관성을 지닌 연구자 의 주관적 평가 및 판단을 통해 나타날 수 있는 편향성을 줄 이고 연구방법의 객관성을 확보하기 위해 노력하였다.

기본적으로 자료조사, 심층면담, 관찰을 통해 수집된 자 료를 통합하였고 이를 바탕으로 하여 각 조직의 세부 활동

Table 1. Subject of Depth Interview

\begin{tabular}{|c|c|c|}
\hline & Subject & Role (Expertize) \\
\hline \multirow{3}{*}{$\begin{array}{l}\text { Foot } \\
\text { Golf }\end{array}$} & A & Manager (Sport Management) \\
\hline & B & Board Member (Sport Category_Golf) \\
\hline & $\mathrm{C}$ & $\begin{array}{l}\text { Advisory Committee Member } \\
\text { (Sport Management) }\end{array}$ \\
\hline \multirow{3}{*}{$\begin{array}{l}\text { Women } \\
\text { Football }\end{array}$} & $\mathrm{D}$ & Co-founder (Physical Education) \\
\hline & $\mathrm{E}$ & Manager (Event Operation) \\
\hline & $\mathrm{F}$ & $\begin{array}{l}\text { Advisory Committee Member } \\
\text { (Sport Category_Football) }\end{array}$ \\
\hline \multirow{3}{*}{$\begin{array}{l}\text { Street } \\
\text { Culture }\end{array}$} & G & Manager (Sport Management) \\
\hline & I & Board Member (Content Creation) \\
\hline & $\mathrm{J}$ & $\begin{array}{l}\text { Advisory Committee Member } \\
\text { (Space Management) }\end{array}$ \\
\hline
\end{tabular}

내역들에 대한 내용분석을 진행하여 요인을 도출하였다. 이 후 도출된 요인을 바탕으로 범주화 및 항목화를 진행하였 다. 이는 3 단계로 진행되었으며 첫 번째 단계에서는 개별적 으로 내용분석 결과를 범주화하였고, 두 번째 단계에서는 상호 결과 공유를 통해 의견 수렴 과정을 진행하였으며 반영 이 필요하다고 생각되는 부분을 개별 결과에 적용하였다. 세 번째 단계에서는 통합 논의를 통해 최종적인 범주화 결과 를 도출하고 이를 바탕으로 주요 활동을 항목화하였다.

다음으로 위의 범주화 및 항목화 과정을 통해 도출된 결 과를 바탕으로 하여 3명의 코더들은 다시 Seifried, Katz, \& Tutka (2017)의 연구에서 제시한 혁신 확산 과정 모델의 단계를 바탕으로 범주화를 진행하였다. 첫 번째 단계에서는 혁신 확산 과정 모델에서 제시하고 있는 각 단계 별로 앞서 진행한 범주화 및 항목화를 통해 도출된 주요 활동을 범주화 하였다. 두 번째 단계에서는 상호 도출된 결과를 교환하여 의견 과정을 진행하였다. 세 번째 단계에서는 통합 논의를 진행하여 최종적인 범주화 결과를 도출하였다.

\section{연구결과}

수집된 자료에 대한 분석 과정을 통해 혁신 확산 과정 모 델에서 제시하고 있는 9가지 단계 별로 주요 활동에 대한 결 과를 도출하였다. 첫 번째 단계인 외부적 충격 단계의 경우 콘텐츠 인지와 문제점 확인과 같은 주요 활동이 나타났다. 본 연구의 대상 중 하나인 풋골프를 국내에 도입한 주체는 골 프 관련 국제 박람회를 통해 풋골프라는 콘텐츠를 인지하였 다. 두 번째 연구 대상인 여자축구 콘텐츠의 주체는 기존 조 직의 문제점들에 대한 인지에서 시작되었다. 세 번째 연구 대상인 스트릿컬처 콘텐츠 주체는 해당 콘텐츠를 적용해 볼 수 있는 방치되어 있던 유휴공간을 발견한 것이 시작이었다.

"처음에 풋골프...이게 뭐지라는 생각이 들었어요. 바로 어떻게 하는
건지도 떠오르지도 않았고. 어디 골프박람회에서 처음 접하게 되었다
고 하더라고요. 그래서 인터넷에서 한참 찾아봤어요. (C, 풋골프,")
"기존 조직의 이사회 회의에 참여를 했는데 다양한 문제점들에 직면
해 있었어요. 가장 중요한 부분은 일단 대회가 개최되고 있지 않았
고, 이로 인해새ㄴㅣㅠㄱㅠ 가입 단체는 물론이고 기존에 있던 가입되어 있
던 단체들도 거의 활동을 하지 않는 상황이었어요. (E, 여자축구)" 
"저기 앞에 있는 저 창고예요. 저 감자창고를 발견하고 저기서 뭘 좀 해보면 좋겠는데, 스트릿컬처가 딱 떠오르면서 시작되었어요 (G. 스트릿컬처"

두 번째 단계로 선도자와의 공식적 연합 단계에서는 조직 내부 및 외부 이해당사자와 결속하는 모습이 나타났다. 구 체적으로, 풋골프 주체는 해당 분야의 권위기관이자 선도기 관으로 볼 수 있는 국제연맹에 설립 조건을 질의하고 지원을 요청하였으며 이미 국제연맹에 가입한 다른 아시아 내 협회 에도 지원을 약속받았다. 이를 바탕으로 하여 국내 이사회 를 구성하고 협력체계를 구축하였다. 여자축구 주체의 경우 는 기존 이사회를 통해 새로운 형태의 연맹의 출범을 제안하 고 관련 설명회를 개최하여 연맹에 가입할 단체를 모집하였 다. 스트릿컬처 주체는 유휴공간 활용 방안에 대한 설명회 개최를 통해 해당 공간을 소유하고 있는 기관을 설득하고 이 사회 구성을 통해 협력체계를 수립하였다.

"우선 이사회를 구성했어요. 서로서로 다른 영역에 있는 분들로 모시 려고 노력했고요. 사실 처음 이런 콘텐츠를 가지고 오게 되면 여러곳 에서 공격을 받을 수 있거든요. 그래서 방패막이 역할을 해 줄 수 있 는 종목, 법률, 회계, 학계 전문가로 최대한 구성했어요. (A, 풋골프)"

"처음에 무슨 이메일을 영어로 보내야 한다고 하더라고요. 그래서 그게 무엇인지 물어보았더니 국제연맹에 가입 조건을 물어봐 달라 는 거예요. 사실 저는 답이 안 올 줄 알았어요. 근대 한 1주일 뒤에 조건들이 쭉 나열되어서 답장이 왔더라고요. (B, 풋골프)

"그냥 허름한감자창고여서 그냥 말만 하면 빌릴 수 있을 줄 알았어요. 근대 그게 아니더라고요. 얼마나 허락을 받아야 되는 사람들이 많은 지... 그래서 그분들을 다 모아서설명회를 열었어요. (G, 스트릿컬처)"

세 번째 단계로서 사회 체계 내 선도자와의 내부적 소통 단계에서는 외부 및 유사 또는 동일 영역의 전문가와 소통하 는 모습들이 나타났으며 동일 영역에 대한 간접 경험 역시 나타났다. 풋골프 주체의 경우 축구 및 골프 전문가와 함께 풋골프라는 종목 특성에 대한 논의를 진행하였으며, 미디어 관계자와 스포츠 기자와는 콘텐츠 확장 가능성에 대한 논의 를 진행하고 자문을 구하였다. 또한 직접적인 풋골프 국제 대회 참관을 통해 국제연맹과 각국 협회 관계자와 함께 의견 을 교환하고 해당 분야에 대한 간접 경험을 쌓아가는 것을 확인할 수 있었다.
"사실 좀 궁금했어요. 풋골프라는게 축구와 골프를 합쳐 놓은 거잖 아요. 그래서 축구 전문가, 골프 전문가를 만나봤어요. 애기를 계속 들어보니 축구하시는 분들은 엄청 관심을 많이 가지시더라고요. 근 대 골프 사람들은 꼭 그렇지는 않았어요. 왜 골프장에서 이런 걸 하 지 이런 느낌도 받고. (A, 풋골프)"

여자축구 주체에 초점을 맞추면 아마추어 축구와 관련된 협회 관계자, 축구 에이전트, 축구 심판 관련 협회 관계자와 의 논의를 진행하였고 자문을 구하는 모습이 나타났다. 이 를 통해 협회 운영, 콘텐츠 확산, 대회 운영 관련 내용에 대 해 소통하는 모습을 보였다. 또한 타 협회가 주관하는 아마 추어 축구 대회 참관을 통해 다양한 의견들을 수렴하는 모습 이 나타났다.

"저희는 롤 모델이 필요했어요. 다른 아마추어를 대상으로 하고 있 는 단체들은 어찌하고 있는지가 무척 궁금했죠. 그래서 기존에 있던 남자축구... 이 단어가 좀 어색하긴 한데 그분들을 만났어. 조금 놀 랐던 사실은 가입되어 있는 단체 수가 굉장히 많고 전국적으로 펼쳐 져 있더라고요. (E, 여자축구)"

"다른 단체의 대회 예산을 보니까 심판에게 지급되는 비용이 엄청 많은 부분을 차지하더라고요. 그렇다고 공식 심판 없이 경기를 진행 했다가는 가입 단체들한테 외면 받을 수 있어서 제가 직접 그분들을 만나서 자문을 구했어요. (F, 여자축구)"

스트릿컬처 주체는 콘텐츠 크리에이터, 부동산 전문가와 의 논의를 통해 각각 스트릿컬처 중심의 유휴공간 활용 방안 에 대한 의견을 교환하였다. 또한 해당 지역 축제 관계자와 의 자문 회의 진행을 통해 스트릿컬처를 중심으로 한 지역 내 공간 운영에 있어 준비할 점 또는 특이점에 대한 내용을 확인하였다. 첫 번째, 두 번째, 세 번째 단계에 대한 구체적 내용은 〈Table 2)를 통해 제시하였다.

네 번째 단계인 구체적 혁신 선택 단계에서는 국제연맹에 소속되고 새로운 조직을 구축하였으며 사용 가능 공간을 실 제로 확보하는 것과 같은 주요 활동이 나타났다. 풋골프 주 체의 경우 국제연맹에 제출한 지원서가 가입 조건에 모두 부 합되어 국내 협회 설립이 승인되었으며, 여자축구 주체는 연맹에 대학 단위의 여자축구 동아리 팀이 입회하는 모습이 나타났다. 스트릿컬처 주체의 경우는 유휴공간 임대 절차를 완료하고 해당 공간을 활용하여 스트릿컬처 콘텐츠를 개발 할 수 있게 되었다. 
Table 2. Analysis results by step: exogenous shock, alliance, communication

\begin{tabular}{|c|c|c|}
\hline Stage & Subject & Activity: Content (Resource) \\
\hline \multirow{3}{*}{$\begin{array}{l}\text { Exogenous } \\
\text { shocks }\end{array}$} & \multirow{2}{*}{ Content recognition } & Recognizing footgolf as content: Visit the international golf fair (DI-FG) \\
\hline & & Recognizing neglected idle space: Live in local aea (DI-SC) \\
\hline & Problem identification & $\begin{array}{l}\text { Expressing and confronting existing alliance problems } \\
\text { : Activity for existing organization (DI-WF) }\end{array}$ \\
\hline \multirow{5}{*}{$\begin{array}{l}\text { Formal coalition of } \\
\text { opinion leaders }\end{array}$} & \multirow{2}{*}{$\begin{array}{l}\text { The organization } \\
\text { unity of internal } \\
\text { stakeholder }\end{array}$} & $\begin{array}{l}\text { Composing board members } \\
\text { : Appointment of board directors and auditors (DI/OV-FG, OV-SC) }\end{array}$ \\
\hline & & $\begin{array}{l}\text { Recruiting affiliated organizations } \\
\text { : Holding a briefing session related to new form of alliance }(\mathrm{OV}-\mathrm{WF})\end{array}$ \\
\hline & \multirow{3}{*}{$\begin{array}{l}\text { The organization } \\
\text { unity of external } \\
\text { stakeholder }\end{array}$} & $\begin{array}{l}\text { Checking qualification for joining international federation / Request for support } \\
\text { : Communication with International federation (DI-FG) }\end{array}$ \\
\hline & & $\begin{array}{l}\text { Requesting support for existing Asian associations } \\
\text { : Participated in the Asian regional presidency meeting (LS-FG) }\end{array}$ \\
\hline & & $\begin{array}{l}\text { Contacting space ownership group } \\
\text { : Holding a briefing session on how to use it (DI-SC) }\end{array}$ \\
\hline \multirow{10}{*}{$\begin{array}{l}\text { Internal communication } \\
\text { between the opinion } \\
\text { leaders of the social } \\
\text { system }\end{array}$} & \multirow{4}{*}{$\begin{array}{l}\text { Expert communication } \\
\quad \text { (External area) }\end{array}$} & $\begin{array}{l}\text { Conducting advisory meetings with media officials } \\
\text { : Communication on the possibility of spreading content (OV-FG) }\end{array}$ \\
\hline & & $\begin{array}{l}\text { Conducting advisory meetings with content creators } \\
\text { : Communication about idle space contents (DI/OV-SC) }\end{array}$ \\
\hline & & $\begin{array}{l}\text { Conducting advisory meetings with real estate experts } \\
\text { : Communication on idle space development and operation (OV-SC) }\end{array}$ \\
\hline & & $\begin{array}{l}\text { Conducting advisory meetings with local festival managers } \\
\text { : Share experiences related to local festival \& facility operation (OV-SC) }\end{array}$ \\
\hline & \multirow{4}{*}{$\begin{array}{l}\text { Expert communication } \\
\text { (Similar \& same area) }\end{array}$} & $\begin{array}{l}\text { Conducting advisory meetings with football \& golf officials } \\
\text { : Communication on the characteristics of the event (DI-FG) }\end{array}$ \\
\hline & & $\begin{array}{l}\text { Advising other amateur football associations } \\
\text { : Share organizational experience (DI-WF) }\end{array}$ \\
\hline & & $\begin{array}{l}\text { Conducting advisory meetings with football agencies } \\
\text { : Communication on the possibility of spreading content (OV-WF) }\end{array}$ \\
\hline & & $\begin{array}{l}\text { Conducting advisory meetings with football referee associations } \\
\text { : Communication related to competition management (DI-WF) }\end{array}$ \\
\hline & \multirow{2}{*}{$\begin{array}{l}\text { Indirect experience } \\
\quad \text { (Same area) }\end{array}$} & $\begin{array}{l}\text { Visiting other amateur football association competitions } \\
\text { : Share experience in running the competition (OV-WF) }\end{array}$ \\
\hline & & $\begin{array}{l}\text { Visiting International footgolf competition } \\
\text { : Share experiences with foot golf officials (LS-FG) }\end{array}$ \\
\hline
\end{tabular}


“그날 정말 기분이 좋았어요. 드디어 오케이를 받는 날이었어요. 임 대료를 내기는 해야 됐지만 꿈에 그리던 저 창고를 이제 사용할 수 있다는 생각에 정말 신나더라고요. (G, 스트릿컬처)"

다섯 번째 단계인 인력 구성 및 조직 구축 단계에서는 조 직 형태를 구축하고 조직 내부 및 외부 인력을 확보하는 모 습이 나타났다. 풋골프, 여자축구, 스트릿컬처 주체 모두 사 단법인과 임의단체와 같은 법인 또는 단체와 같은 형식을 갖 추었다. 또한 여자축구 관련 주체는 내부 관리자를 포함한 자원봉사 집단 및 서포터즈를 구성하였다. 한편 스트릿컬처 주체는 외부 전문가 네트워크 구축을 통해 콘텐츠를 개발하 고 공간을 운영할 수 있는 협업 체제를 형성하였다.

"제가 총괄로 조직을 한번 운영해 본다고 애기했어요. 이게 고정적 으로 돈을 받는 것도 아니고 공식적으로 직위가 생기는 건 아니지만 그냥 재미있을 것 같고 좋은 경험일 것 같았어요. 새로운 종목을 하 나 가져온다는 게. (A, 풋골프)"
"인력을 채용하고 이를 체계화할 돈도 시간도 없었어요. 그래서 여 자축구를 좋아하는 학부생들을 중심으로 해서 서포터스를 한번 결 성해 보면 어떨까라는 제안을 했어요. (F, 여자축구)"

\section{“공간이라는 부분 그리고스트릿컬처라는 영역 모두가 전문성이 있 어야 하거나 아님 개별 영역에 아주 정통한 사람이 필요하다는 생각 을 하게 됐죠. 그래서 이러한 전문가들을 채용할 수는 없으니 이벤 트를 기반으로 해서 협력 체계를 만드는 쪽으로 노력해 봤어요. (I, 스트릿컬처)"}

여섯 번째 단계인 혁신의 발전 및 전파 단계에서는 온라인 소통 채널을 구축하는 활동 모습이 나타났다. 풋골프, 여자 축구, 스트릿컬처 주체 모두 자체 홈페이지와 SNS를 활용하 여 활동 내역을 공유하였으며 이를 통해 발생한 피드백을 수 집하였다. 여자축구 관련 조직의 경우 영상을 자체 제작하여 활동 모습을 보다 생동감 있고 재미있는 모습으로 전하기 위 한 노력이 보였다. 네 번째, 다섯 번째, 여섯 번째 단계에 대 한 구체적 내용은 〈Table 3〉을 통해 제시하였다.

Table 3. Analysis results by step: innovation selection, organizational composition, innovation diffusion

\begin{tabular}{|c|c|c|}
\hline Stage & Subject & Activity: Content (Resource) \\
\hline \multirow{3}{*}{$\begin{array}{l}\text { Decision to select a } \\
\text { specific innovation }\end{array}$} & $\begin{array}{l}\text { Belonging to } \\
\text { international organizations }\end{array}$ & $\begin{array}{l}\text { Establishing approved by the international federation } \\
\text { : Submission of application for establishment of association (LS-FG) }\end{array}$ \\
\hline & $\begin{array}{l}\text { Establishing new } \\
\text { organization }\end{array}$ & Building a new form of alliance: Board meeting held (DI-WF) \\
\hline & $\begin{array}{l}\text { Getting approval for using } \\
\text { idle space }\end{array}$ & Completing idle space rental: Idle space rental procedure in progress (DI-SC) \\
\hline \multirow{5}{*}{$\begin{array}{l}\text { Recruitment and/or the } \\
\text { establishment of } \\
\text { boundary spanners }\end{array}$} & \multirow{2}{*}{$\begin{array}{l}\text { Building organizational } \\
\text { form }\end{array}$} & $\begin{array}{l}\text { Registering as a non-profit corporation } \\
\text { : Submit documents to the competent authority (LS-FG, OV-SC) }\end{array}$ \\
\hline & & $\begin{array}{l}\text { Registering as voluntary group } \\
\text { : Submit documents to the competent authority (LS-WF) }\end{array}$ \\
\hline & $\begin{array}{l}\text { Securing internal } \\
\text { human resource }\end{array}$ & Securing general manger: Expansion of core human resource (DI-FG, DI-WF) \\
\hline & \multirow{2}{*}{$\begin{array}{l}\text { Securing external } \\
\text { human resource }\end{array}$} & Formating supporters: Expansion of support staff (DI-WF) \\
\hline & & Establishing expert cooperation system: Secure experts (DI-SC) \\
\hline \multirow{2}{*}{$\begin{array}{l}\text { Develop and introduce } \\
\text { the innovation }\end{array}$} & \multirow{2}{*}{$\begin{array}{l}\text { Establishing online } \\
\text { communication channels }\end{array}$} & $\begin{array}{l}\text { Posting content on homepage \& SNS } \\
\text { : Share major activities and collect feedback (LS-FG, LS-WF, LS-SC) }\end{array}$ \\
\hline & & $\begin{array}{l}\text { Posting video-type content on SNS } \\
\text { : Share created video and collect feedback (LS-WF) }\end{array}$ \\
\hline
\end{tabular}

DI-Depth Interview, LS-Literature Search, OV-Observation, FG-FootGolf, WF-Women Football, SC-Street Culture 
Table 4. Analysis results for stage: media utilization, practical diffusion, securing sustainability

\begin{tabular}{|c|c|c|}
\hline Stage & Subject & Activity: Content (Resource) \\
\hline \multirow{3}{*}{ Mass media outlets } & Media & $\begin{array}{c}\text { Appearing media article } \\
: \text { Share host competition / International competitions participation (LS-FG) } \\
: \text { Share host competition (LS-WF) } \\
: \text { Share host exhibition (LS-SC) }\end{array}$ \\
\hline & Public lecture & $\begin{array}{l}\text { Giving lecture } \\
\text { Share content introduction and introduction process (OV-FG) }\end{array}$ \\
\hline & Academic conference & $\begin{array}{l}\text { Participating in academic conference } \\
\text { : Share experience in education programs (OV-SC) }\end{array}$ \\
\hline \multirow{7}{*}{$\begin{array}{l}\text { Actual diffusion of an } \\
\text { innovation }\end{array}$} & \multirow{3}{*}{$\begin{array}{l}\text { Conducting experience \& } \\
\text { education program }\end{array}$} & $\begin{array}{c}\text { Hosting footgolf experience event } \\
\text { : Collaboration with University Festival (LS-FG) }\end{array}$ \\
\hline & & $\begin{array}{l}\text { Hosting footgolf experience event } \\
\text { : Collaboration with professional golf competitions organizer (LS-FG) }\end{array}$ \\
\hline & & $\begin{array}{l}\text { Conducting education program } \\
\text { : Development of educational contents suitable for idle space (DI/LS-SC) }\end{array}$ \\
\hline & \multirow[t]{2}{*}{$\begin{array}{l}\text { Hosting competitions \& } \\
\text { exhibitions }\end{array}$} & $\begin{array}{l}\text { Hosting competition } \\
\text { : Cooperation with sports facilities operated by public institutions (LS-FG) } \\
: \text { Collaboration with universities \& using university facilities (DI/LS-WF) } \\
\text { : Collaboration with local governments \& securing local facilities/subsidies } \\
\text { (DI/LS-SC) }\end{array}$ \\
\hline & & $\begin{array}{l}\text { Hosting exhibition } \\
\text { : Development of exhibition contents suitable for idle spaces (DI/LS-SC) }\end{array}$ \\
\hline & Building infrastructure & $\begin{array}{l}\text { Constructing footgolf experience venue } \\
\text { : Use of idle space in local area (DI-FG) }\end{array}$ \\
\hline & $\begin{array}{l}\text { Participating } \\
\text { international competition }\end{array}$ & $\begin{array}{c}\text { Participating international competitions } \\
\text { Composition and dispatch of representative players (DI/LS-FG) }\end{array}$ \\
\hline \multirow{3}{*}{$\begin{array}{l}\text { Decisions to continue, } \\
\text { discontinue, or re-invent } \\
\text { the existing innovation } \\
\text { must occur }\end{array}$} & \multirow{2}{*}{ Internal evaluation } & $\begin{array}{l}\text { Holding board of directors } \\
\text { : Share annual activities and collect opinions (OV-FG/SC) }\end{array}$ \\
\hline & & $\begin{array}{l}\text { Holding meeting with the captains } \\
\text { : Share annual activities and collect opinions (OV-WF) }\end{array}$ \\
\hline & External evaluation & $\begin{array}{l}\text { Getting consultation for contents } \\
\text { : Find out future content (DI-SC) }\end{array}$ \\
\hline
\end{tabular}

DI-Depth Interview, LS-Literature Search, OV-Observation, FG-FootGolf, WF-Women Football, SC-Street Culture 
일곱 번째 단계인 대중 매체 활용 단계에서는 언론사, 강 연, 학술대회를 활용하는 모습들이 나타났다. 풋골프, 여자 축구, 스트릿컬처 주체는 대회 개최, 대회 참가, 전시회 개최 와 같은 내용들을 언론 기사로 송출하였고 풋골프와 스트릿 컬처 주체의 경우는 각각 강연 진행 및 학술대회 참가를 통 해 콘텐츠를 소개하고 도입과정과 함께 교육 프로그램 진행 경험을 공유하는 모습을 보였다.

여덟 번째 단계인 혁신의 실제적 확산 단계에서는 자체 체험 및 교육 프로그램을 진행하고 대회 및 전시회를 개최하 는 모습이 나타났다. 또한 이와 함께 인프라를 구축하고 실 제 국제 대회에 참가하는 모습도 나타났다. 풋골프 주체의 경우 풋골프를 체험할 수 있는 이벤트 및 대회 개최와 함께 국제 대회에 참가하는 모습이 나타났다. 또한 풋골프 경기 를 할 수 있는 경기장 구축을 진행하였다. 여자축구 주체는 대학 또는 지자체와의 협업을 통해 여자축구 대회를 개최하 였다. 스트릿컬처 주체는 자체적으로 전시회를 열고 교육 콘텐츠 개발하여 프로그램을 진행하는 모습을 보였다.

\section{“임대료가 너무 아까웠어요. 아무것도 안 해도 고정적으로 그냥 계 속 나가니까. 뭐라도 해아겠다는 생각이 들었어요. 그래서 동네 아 이들을 불러서 뭐라도 가르쳤어요 창고에서. 직접 교육 프로그램 만 들고 교재, 재료는 여기저기서 얻어오고 그렇게 시작했어요. $(\mathrm{H}$, 스 트릿컬처"}

"이것 참 대회를 열어야 하는데 뭐 이렇게 돈이 들어가는 게 많은지. 그래서 우선은 가입 단체가 있는 학교에 부탁을 했어요. 운동장만 좀 빌려 달라 나머지는 우리가 알아서 해보겠다. 그래서 운동장을 무상으로 빌릴 수 있었어요. 다음으로 운이 좋게 지자체랑 연결이 되었어요. 거기서 숙박, 경기시설과 같은 부분을 지원해 주는 조건 으로 경기를 개최할 수 있게 되었어요. (E, 여자축구)"

\section{"저희가 드디어 월드컵에 나갈 수 있게 되었어요. 기쁘기는 했는데 장소가 아르헨티나여서... 여기저기서 스폰서를 구하기는 했는데 사실 어디서 돈이 다마련되었는지는 잘 모르겠어요. 아무튼 지구를 한 바퀴를 돌아 아르헨티나에 4 명의 선수를 파견할 수 있었어요. 정 말 잘 모르지만 70년대에는 이렇게 어렵게 선수들이 국제 대회에 출전하지 않았을까 싶었어요. (A, 풋골프)"}

마지막으로 아홉 번째 단계인 혁신에 대한 지속 여부 및 재혁신 여부 결정 단계에서는 조직 내부 및 외부 평가가 진 행되었다. 풋골프, 여자축구, 스트릿컬처 주체 모두 이사회 또는 주장단 간담회를 개최하여 연간 활동 내용에 대해 공유
하고 관련된 피드백을 수집하였고 주요 사안에 대한 의사결 정을 진행하였다. 스크릿컬처의 경우는 미래 콘텐츠 구상을 위해 콘텐츠 컨설팅을 진행하는 모습이 나타났다. 일곱 번 째, 여덟 번째, 아홉 번째 단계에 대한 구체적 내용은 〈Table 4〉를 통해 제시하였다.

"스트릿컬처가 참 광범위한 것 같아요. 저희가 정의하기 나름이기도
하고요. 처음에는 단순히 엑스게임 연장 선상에서 스포츠 종목에 관
심이 있어서 시작했거든요. 그런데 그것만 있는 게 아니어서 전문가
들한테 좀 조언을 구해아겠다는 생각이 들었어요. (H, 스트릿컬처)"

\section{논 의}

도출된 결과를 세 가지 범주로 구분 지어 살펴보면 첫 번째 부터 세 번째 단계까지는 사례 별 특정 자극을 바탕으로 새로 운 콘텐츠를 도입하기 위한 동기가 발생하였고 선도자들과의 연합과 소통을 위한 노력이 나타났다. 네 번째부터 여섯 번째 단계까지는 콘텐츠 국내 도입을 구체화시키고 운영을 위한 조 직 구축과 함께 콘텐츠를 알리기 위한 노력들이 나타났다. 마 지막으로 일곱 번째 단계에서 마지막 단계까지는 대중 매체 또 는 상호 소통 가능한 이벤트를 통해 실제적으로 콘텐츠를 확산 시키려는 노력이 보였고 진행된 일련의 과정을 평가하는 모습 이 나타났다.

먼저, 첫 번째부터 세 번째까지의 단계를 살펴보면 외부적 충격 단계의 경우 콘텐츠를 인지하고 문제를 확인하는 모습이 나타났고 선도자와의 공식적 연합 단계에서는 조직 내부와 외 부 이해당사자와 결속하는 모습이, 사회 체계 내 선도자와의 내부적 소통 단계에서는 내부 및 외부 전문가와의 소통하는 모 습들이 나타났다. 이를 통해 첫 번째부터 세 번째 단계까지는 외부 충격으로 인해 기회를 발견하는 과정이 진행되었음을 알 수 있다.

이는 경로의존성이 우연한 사건으로 인해 고착화되는 형상 에 대한 비판으로서 나타난 경로생성으로 설명할 수 있다. Meyer \& Schubert (2007)의 연구에 따르면 경로생성은 기존 경로의 자연스러운 소멸, 환경 변화, 특정 의도를 가진 개인에 의해 발생할 수 있다고 설명한다. Garud \& Karnoe (2001)와 David (2001)의 연구에서는 주요 이해당사자들의 기존 규칙 또는 제도에 대한 의도적인 일탈로, 새로운 경로가 생성되며 이를 발전시키기 위한 능동적인 모습이 나타난다고 설명하였 
다. 이렇게 경로가 생성되는 과정은 문화가 확산되어 나가는 초기 세 단계와 유사한 모습이라 할 수 있으며 기존의 주류 문 화에서 새로운 문화 진입하는 초기의 과정을 새로운 경로생성 과 유사한 모습이라 할 수 있다.

또한 Kaufman \& Patterson (2005)의 연구에서 제시하고 있는 문화확산을 성공시키기 위한 필요조건과 본 연구 결과를 연결지어 설명할 수 있다. 해당 연구에서는 문화 확산의 첫 번 째 성공 조건으로서 도입하려는 콘텐츠가 사회 지도층의 요구 에 부합되어야 하며, 두 번째로는 문화적 선도가들이 해당 콘 텐츠에 매력을 느껴야 한다고 설명한다. 본 연구 대상들이 초 기 단계에서 선도자들과 소통하고, 연대하고, 논의하는 일련 의 모습들은 Kaufman \& Patterson (2005)의 연구를 통해서 도 해석될 수 있다.

본 연구 결과, 초기 단계를 거치고 난 이후 네 번째 단계부 터 여섯 번째 단계로써, 우선 구체적 혁신 선택 단계에서는 국 제 조직에 소속, 새로운 조직 구축, 사용 가능 공간 확보와 같 은 모습이 나타났고 다음 단계에서는 조직 형태를 구축하고 조 직 내부 인력과 함께 외부 전문가를 확보하기 위한 노력이 나 타났다. 혁신의 발전 및 전파 단계에서는 온라인 소통 채널을 구축하고 이를 활용하는 모습이 나타났다.

도출된 결과에 따르면 새로운 콘텐츠를 도입한 조직은 인력 구축 후, SNS 등을 통해 온라인 홍보를 적극 해온 것을 알 수 있다. 이는 Fan, Kim, \& Cui (2010)의 연구에서 제시한 시장 의 신규 공급자가 시장 진입을 위해 활용한 전략과 유사한 형태 라 할 수 있다. 해당 연구에서 제시한 제품 촉진, 가격 촉진, 유 통 촉진, 홍보 촉진의 전략 중 홍보 촉진으로 설명될 수 있다. 본 연구의 분석 대상으로서 신규 콘텐츠를 시장에 확산시킨 사 례들을 통해 각 주체들이 SNS를 활용하여 수행한 일련의 활동 과 제작된 영상들의 공유를 통해 새로운 시장에 콘텐츠를 알리 기 위해 노력하였다는 것을 알 수 있다.

마지막으로 일곱 번째 단계부터 마지막 단계의 경우 대중 매체 활용 단계에서는 언론사, 강연, 학술대회를 활용하여 콘 텐츠를 알리기 위한 노력이 지속되었고, 혁신의 실제적 확산 단계에서는 체험 및 교육 프로그램 진행, 대회 또는 전시회를 개최하는 모습이 분석 결과로 도출되었다. 이와 함께 시설을 구축하고 실제 국제 대회에 참가하는 모습도 보였다. 혁신에 대한 지속 여부 및 재혁신 여부 결정 단계에서는 조직 내부 인 력과 외부 전문가를 통한 평가가 진행되었다.

이러한 과정은 특정 골프 시뮬레이터 회사가 국내 시장에 골프 시뮬레이터를 확산시켜 나간 일련의 과정과 유사했다.
소위 스크린 골프라고 지칭되는 골프 시뮬레이터를 새로운 시 장에 확산시키려는 주체는 스크린 골프를 하나의 게임이자, 노래방 문화 같은 놀이 문화가 아닌 하나의 스포츠 콘텐츠로써 시장 내에 확산시키고자 했다. 이를 위해 언론 매체를 적극적 으로 활용하여 공신력을 얻으려는 모습과 본 연구의 결과가 맥 을 같이하는 것으로 볼 수 있다.

구체적으로, Lee \& Joo (2020)의 연구에 따르면 20182019년 기간 동안, 온라인 매체를 통해 골프 시뮬레이터와 관 련한 특정 회사의 상호는 3,152회, 스크린골프는 1,944회 검 색되었다는 것을 알 수 있었다. 이는 새로운 콘텐츠를 확산시 키기 위해 온라인 매체를 적극적으로 활용하고 있다는 것을 나 타냈다. 나아가 특정 골프 시뮬레이터 회사는 골프 시뮬레이터 를 활용한 프로와 아마추어 대회, 스크린골프 콘텐츠 확산을 위한 방송 채널을 개국하여 사람들이 자연스럽게 대회를 관람 하고 직접 참여하도록 유도하여 시장에서 콘텐츠가 확산되어 나갈 수 있는 발판을 마련하였다.

본 연구가 학문적으로 의미 있는 부분은 혁신 확산 과정 모 델을 바탕으로 하여 스포츠 콘텐츠가 국내에 도입되는 세부 과 정을 분석하였다는 것이다. 창업이 새로운 기회를 마련하고 시장을 확장해 나가는 것이라는 관점에서 스포츠 창업 과정에 대한 분석을 통해 스포츠 콘텐츠 기반 창업의 성공 및 지속 가 능성을 확보하기 위한 연구는 필요하다. 왜냐하면 성공적인 과정 설계를 통해 목표 달성과 지속 가능성을 확보할 수 있는 가능성을 높일 수 있기 때문이다. 본 연구에서는 이러한 과정 분석을 위한 틀을 제시하였다. 추후 연구에서는 해당 분석 틀 을 활용하여 다양한 사례를 분석해 나갈 수 있으며 이를 통해 창업 과정을 일반화시켜 나갈 수 있다고 판단된다.

실무적으로는 도출된 결과를 스포츠 콘텐츠 도입, 더 나아 가 스포츠 콘텐츠 중심의 창업을 해나가는 데 있어 하나의 가이 드라인으로서 활용할 수 있다. 창업은 보통 소규모 집단에서 새로운 접근 방식으로 진행되는 경우가 많기 때문에 지금 현재 어떠한 위치인지 또는 잘 해나가고 있는지에 대한 의문을 시시 각각 가지게 된다. 이러한 상황 속에서 각 조직의 방향성 또는 진척 정도를 확인할 수 있는 가이드라인이 반드시 필요하며 본 연구에서 제시한 결과가 도움을 줄 수 있을 것으로 판단된다.

\section{결론 및 제언}

본 연구의 목적은 해외에서 새롭게 생성되거나, 선진화 
된 형태의 스포츠 콘텐츠를 국내시장에 새롭게 도입하여 확 산시켜 나가는 창업 과정을 혁신 확산 과정 모델을 적용하여 분석하는 것이다. 결과 도출을 위해 질적연구방법을 활용하 였고 자료조사, 심층면담, 관찰을 통해 자료를 수집하였다. 수집된 자료는 내용분석을 기초로 범주화 및 항목화를 통해 분석되었다. 분석을 통해 혁신 확산 과정 단계 별로 각 조직 이 수행한 활동을 범주화할 수 있었다.

연구의 제한점은 영리를 추구하는 콘텐츠와 관계된 기업 보다는 비영리를 추구하는 조직을 중심으로 연구를 진행하 였다는 점이다. 따라서 추후 연구에서는 영리적 성격의 조 직을 대상으로 연구를 진행하여 본 연구의 한계를 보완할 수 있다. 또한 본 연구는 시장에 콘텐츠를 도입하기 위한 창업 초기 단계의 주체들을 대상으로 연구를 진행했다. 따라서 향후 창업 중기, 또는 이후 단계에 초점을 맞추어 연구를 진 행할 수 있다. 도출된 결과를 통하여 확산 과정의 각 단계에 나타나는 활동 모습을 보다 일반화시킬 수 있다.

이와 함께 분석 대상이 된 콘텐츠가 풋골프, 여자축구, 스 트릿컬처로써 그 특성이 상이하다고 볼 수 있음에도 불구하 고 이를 동일한 층위에서 분석하여 일반화했다는 것이다. 다만, 세 가지 콘텐츠는 대중화가 덜 된 콘텐츠라는 점에서 공통점을 지니고 있지만, 추후 연구에서는 개별 콘텐츠에 집중하여 각 콘텐츠별로 주체의 활동 과정에 대한 결과를 도 출해 낼 수 있다.

본 연구를 통해 국내시장에 없는 콘텐츠를 국내 또는 국 내 시장에 도입하여 확산시키는 것은 창업 형태 중 하나로 간주될 수 있다는 것을 알 수 있다. 이를 위해 새로운 시장에 콘텐츠를 확산시키는데 있어 각 단계별로 수행해야 할 활동 들이 있다고 판단된다. 본 연구를 통해 스포츠 콘텐츠 중심 의 창업 활동을 지원하는데 있어 지원 내용, 지원 규모, 지원 단계 등 보다 구체적이고 실효성 있는 적절한 지원이 이루어 질 수 있기를 기대한다.

\section{참고문헌}

Altheide, D. (1996). Qualitative Media Analysis. Sage, CA Alvarez, S. A., Barney, J. B., \& Young, S. L. (2010). Debates in entrepreneurship: Opportunity formation and implications for the field of entrepreneurship. In Handbook of entrepreneurship research (pp. 23-45). Springer, New
York, NY.

Busenitz, L. W., West III, G. P., Shepherd, D., Nelson, T., Chandler, G. N., \& Zacharakis, A. (2003). Entrepreneurship research in emergence: Past trends and future directions. Journal of management, 29(3), 285-308.

Casson, M. (1982). The entrepreneur: An economic theory. Rowman \& Littlefield.

Creswell, J. W. (2003). A framework for design. Research design: Qualitative, quantitative, and mixed methods approach (2nd ed.). Sage.

David, P. A. (2001). Path dependence, its critics and the quest for 'historical economics'. Evolution and path dependence in economic ideas: Past and present, 15, 40.

Dimov, D. (2007). From opportunity insight to opportunity intention: The importance of person situation learning match. Entrepreneurship Theory and Practice, 31(4), 561-583.

Eagleman, A. N. (2011). Stereotypes of race and nationality: Sport magazine coverage of MLB players from 2000 to 2007. Journal of Sport Management, 25(2), 156-168.

Eckhardt, J. T. \& Shane, S. A. (2003). Opportunities and entrepreneurship. Journal of Management, 29(3), 333-349.

Fan, Q., Kim, W., \& Cui, G. (2010). Influence of Marketing Mix on Customer's Attitude and Purchase Intention: Mediating Effects of Customer Experiences. The Korea Contents Society, 10(8), 292-300.

Fiet, J. O. (2007). A prescriptive analysis of search and discovery. Journal of Management Studies, 44(4), 592 - 611.

Garud, R., \& Karnoe, P. (Eds.). (2001). Path dependence and creation. Psychology Press.

Israel, K. (1973). Competition and entrepreneurship. The university of Chicago Press.

Kaufman, J. \& Patterson, O. (2005). Cross-national cultural diffusion: The global spread of cricket. American sociological review, 70(1), 82-110.

Kim, J. (2020, September). [2020국감]창업기업 $70 \%, 5$ 년도 못 버틴대(Korean Title Only). Edaily. Retrieved by https://www.edaily.co.kr/news/read?newsId=01436646625 931280\&mediaCodeNo=257\&ref=bm

Kirzner, I. M. (1997). Entrepreneurial discovery and the competitive market process: An Austrian approach. Journal of economic Literature, 35(1), 60-85. 
Lee, Y. \& Joo, H. (2020). A Study on the Recognition of Screen Golf Using Big Data Analysis: Focusing on Golf-zone. The Korea Journal of Sports Science, 29(2), 535-547.

Logan, M. S. \& Ganster, D. C. (2007). The effects of empowerment on attitudes and performance: The role of social support and empowerment beliefs. Journal of Management Studies, 44(8), 1523-1550.

Lumpkin, G. T. \& Lichtenstein, B. B. (2005). The role of organizational learning in the opportunity recognition process. Entrepreneurship Theory and Practice, 29(4), 451 472.

Meyer, U. \& Schubert, C. (2007). Integrating path dependency and path creation in a general understanding of path constitution. The role of agency and institutions in the stabilisation of technological innovations. Science, Technology \& Innovation studies, 3(1), 23-44.

Peres, R., Muller, E., \& Mahajan, V. (2010). Innovation diffusion and new product growth models: A critical review and research directions. International Journal of Research in Marketing, 27(2), 91-106.

PGA (2017). PGA Merchandise Show Info. Retrieved by http://www.pgashow.com/Show-Info/

Rogers, E. M. (2010). Diffusion of innovations. Simon and Schuster.
Sarasvathy, S. D., Dew, N., Velamuri, S. R., \& Venkataraman, S. (2003). Three views of entrepreneurial opportunity. In Handbook of entrepreneurship research (pp. 141-160). Springer, Boston, MA.

Schroeder, R. G., Buckman, J., \& Cardozo, R. N. (1996). New value creation: The next development in quality management. White Paper, Minneapolis: Carlson School of Management, University of Minnesota.

Schumpeter, J. A. (2013). Capitalism, socialism and democracy. Routledge.

Seifried, C., Katz, M., \& Tutka, P. (2017). A conceptual model on the process of innovation diffusion through a historical review of the United States Armed Forces and their bowl games. Sport Management Review, 20(4), 379-394.

Shane, S. \& Venkataraman, S. (2000). The promise of entrepreneurship as a field of research. Academy of Management Review, 25(1), 217 - 226.

Short, J. C., Ketchen, D. J., Jr, Shook, C. L., \& Ireland, R. D. (2010). The concept of "opportunity" in entrepreneurship research: Past accomplishments and future challenges. Journal of Management, 36(1), 40 - 65.

Strang, D. \& Meyer, J. W. (1993). Institutional conditions for diffusion. Theory and society, 487-511. 


\title{
스포츠 콘텐츠 국내 도입 중심의 창업 과정 분석: 혁신 확산 과정 모델을 중심으로
}

\author{
권기성 ${ }^{1}$, 오태연 ${ }^{2}$, 이지현 ${ }^{3}$, 강지현 ${ }^{4}$ \\ 1강원대학교 조교수 \\ ${ }^{2}$ 미시시피 주립대학교 조교수 \\ ${ }^{3}$ 서울대학교 석사 \\ ${ }^{4}$ 서울대학교 박사수료
}

[목적] 스포츠 콘텐츠를 새로운 시장인 국내에 도입하는 형태의 창업이 다수 진행되고 있으며 창업 성공 가능성을 높이기 위한 창업 단계별 적정한 지원이 필요한 상황이다. 이에 본 연구의 목적은 해외에서 새롭게 생성되거나, 선진화된 형태의 스포츠 콘텐츠를 국내시장에 새롭게 도입하여 확산시켜 나가는 창업 과정을 혁 신 확산 과정 모델을 적용하여 분석하는 것이다. [방법] 결과 도출을 위해 질적연구방법을 활용하였고 심층면 담, 자료수집, 관찰 방법을 통해 자료를 수집하였다. 수집된 자료는 내용분석 결과를 바탕으로 단계별 범주화 및 항목화를 통해 분석되었다. [결과] 결과를 살펴보면 외부적 충격 단계에서는 콘텐츠 인지와 문제 인식이 도출되었고 선도자와의 공식적 연합 단계에서는 조직 내부 및 외부 이해당사자와의 결속이 확인되었다. 사회 체계 내 선도자와의 내부적 소통 단계에서는 외부와 유사 또는 동일 영역의 전문가와 소통하는 모습들이 나타 났다. 구체적 혁신 선택 단계에서는 국제 조직 소속, 새로운 조직 구축, 사용 가능 공간을 확보를 위한 활동이 나타났고 인력 구성 및 조직 구축 단계에서는 조직 내부 및 외부 인력을 확보하고 외부적으로 조직 형태를 갖추려는 노력이 나타났다. 혁신의 발전 및 전파 단계에서는 온라인 소통 채널을 구축하는 모습이 나타났다. 대중 매체 활용 단계에서는 언론사, 강연, 학술대회를 활용하는 모습을 보였고, 혁신의 실제적 확산 단계에서 는 체험 및 교육 프로그램을 진행, 대회 및 전시회를 개최, 시설을 구축 및 실제 국제 대회에 참가하는 모습이 나타났다. 혁신에 대한 지속 여부 및 재혁신 여부 결정 단계에서는 조직 내부와 외부 인사를 통해 평가가 이루 어졌다. [결론] 도출된 각 단계별 활동 모습을 바탕으로 하여 창업의 각 단계별로 필요한 부분을 채워 줄 수 있는 지원 체계를 만들 때 창업의 성공 가능성을 높일 수 있다.

주요어: 창업, 창업과정, 스타트업, 스포츠 스타트업, 스포츠 콘텐츠. 혁신 확산 과정 모델 